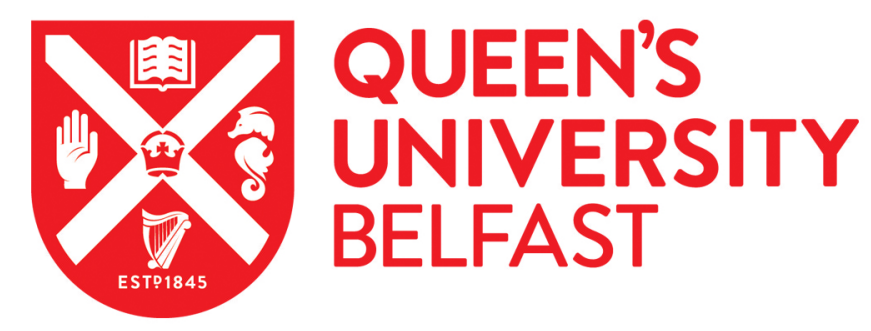

\title{
Young Carers in Northern Ireland: Perceptions of and Responses to Illness and Disability within the Family
}

McGibbon, M., Spratt, T., \& Davidson, G. (2019). Young Carers in Northern Ireland: Perceptions of and Responses to Illness and Disability within the Family. British Journal of Social Work, 49(5), 1162-1179. https://doi.org/10.1093/bjsw/bcy102

Published in:

British Journal of Social Work

Document Version:

Peer reviewed version

Queen's University Belfast - Research Portal:

Link to publication record in Queen's University Belfast Research Portal

Publisher rights

(C) 2018 The Authors. Published by Oxford University Press on behalf of

The British Association of Social Workers. This work is made available online in accordance with the publisher's policies. Please refer to any applicable terms of use of the publisher.

\section{General rights}

Copyright for the publications made accessible via the Queen's University Belfast Research Portal is retained by the author(s) and / or other copyright owners and it is a condition of accessing these publications that users recognise and abide by the legal requirements associated with these rights.

Take down policy

The Research Portal is Queen's institutional repository that provides access to Queen's research output. Every effort has been made to ensure that content in the Research Portal does not infringe any person's rights, or applicable UK laws. If you discover content in the Research Portal that you believe breaches copyright or violates any law, please contact openaccess@qub.ac.uk. 


\title{
Young Carers in Northern Ireland: perceptions of and responses to illness and disability within the family
}

Marlene McGibbon, Trevor Spratt and Gavin Davidson

\section{Accepted for publication by the British Journal of Social Work on $7^{\text {th }}$ October 2018}

\begin{abstract}
$\underline{\text { Abstract }}$
This paper reports findings from a qualitative study undertaken with twenty-two young carers across Northern Ireland aged between eight and eighteen. It focuses on their experiences as informal care givers in households where at least one family member was living with an illness and/or disability. While much has been written about the quantifiable aspects of informal care including the number of hours spent caring and the physical nature of caring tasks, this approach has tended to subsume individual experiences within the category 'young carer' and fails to differentiate between sub populations of children and young people whose caring relationships may be very disparate. Whilst there has been a tendency to focus on the vulnerability of young carers, explanations as to why some experience greater physical, emotional and psychosocial difficulties than others are underdeveloped. It has been suggested that differential outcomes may be attributable to a capacity for resilience, which can lessen vulnerability. The study examined the protective and risk factors, which might help to promote or challenge the resilience of young carers. It was found that knowledge of and response to, both the nature and trajectory of illness or disability, contributed to young carers' capacity for resilience.
\end{abstract}

\section{Introduction}

The introduction of the Children and Families Act 2014 has placed a requirement on local authorities to assess the needs of young carers as an intrinsic part of the assessment 
process. This has placed greater onus on the assessment process being knowledge informed, with particular requirements to better understand the differentiated population of young carers in order to provide bespoke services.

Prior to the 1980s, there appears to have been little recognition of the roles undertaken by children and young people in relation to the provision of informal care within the family and as a result, they have been slow in coming to the attention of academics, researchers and policy makers (Earley et al., 2007). Further, as Thomas and colleagues (2003) have noted, the issue of deciding which children and young people might reasonably be regarded as young carers is a complex and at times controversial subject - so too the nature of interfamilial relationships and when the provision of informal care should become an issue for the state.

Within the literature there has been a tendency to focus on the vulnerability of young carers with research remaining wedded to the negative outcomes associated with their caring roles, including lack of academic success, restricted opportunities, stigma and other psycho-social difficulties (Aldridge, 2018). This has influenced an at times sentimental portrayal of young carers which fails to capture the shared intimacies of family life or, appreciates the challenges faced by children and young people caring for a parent experiencing severe mental health difficulties or a sibling living with some form of developmental disorder. In fact, the wide variety of caring tasks, responsibilities and roles undertaken by young carers tend to challenge attempts to construct classification in terms of defining which children and young people might be recognised as young carers.

The term 'young carer' has also attracted criticism from those who challenge their entitlement to be regarded as a welfare category in their own right, generating a polarity between the children's rights paradigm and that anchored in the rights based approach of the disability movement, the focus of which has concentrated on securing a legal entitlement to appropriate service provision for physically disabled parents in order that they do not have to rely on their children for informal care. However, it may be suggested that this delimitation ignores the reality that children and young people are involved in a range of caring relationships (Devine and Lloyd, 2011) which in turn, can be mediated or compounded by a number of factors including amongst others, the nature of illness 
and/or disability itself, family structure and the availability and willingness of others to become involved in the provision of care.

While many of the studies into the experiences of young carers have originated in the UK, similar research has also emerged from Canada, Australia and Africa. Szafran and colleagues (2016) used focus groups in Edmonton, Canada, to explore five former young carers' views of their experiences. These were largely negative with the participants focusing on their additional caring and household responsibilities; the impact on schooling; the physical and emotional demands involved; and the consequences for their social development and personal relationships in adulthood. Day (2015) reviewed the literature on young carers in the Australian context and concluded that this area has been largely neglected in that context, especially for those aged 18-15, and emphasised the importance of developing robust theoretical perspectives on the issues involved. In South Africa, Lane and colleagues (2015) interviewed 349 young people, aged 10-18, who were caring for adults with HIV and other illnesses. They also reported the level of burden experienced by young carers and the complexities for the roles and relationships involved.

In Northern Ireland, research has mainly employed quantitative data (see for example Devine and Lloyd, 2008; 2011 and Lloyd, 2012). It has been acknowledged, however, (Patient and Client Council, 2009) that qualitative studies reflecting upon children and young people's personal experiences of their care giving roles are necessary to inform both policy and social work practice. This dearth of what Becker (2007) describes as home grown research evidence has led policy makers in Northern Ireland to take direction from elsewhere in the UK - an approach which has come under criticism for failing to move beyond what Gray and Birrell (2013, cited in Duffy et al., 2014) describe as purpose based statements which cannot begin to address the individual needs of young carers. This is perhaps best illustrated in the Review of the Support Provision for Carers (2009, p. 58) which, while discussing the requirement to ensure that young carers do not have to take on inappropriate levels of responsibility for providing care, makes no attempt to qualify what might be considered inappropriate levels of responsibility and alludes to this premise solely in terms of the planning and provision of services. 
As Morgan (2006) has observed, care recipients have different care needs, which in turn are likely to influence young carers' experiences of care giving in very disparate ways. According to Gladstone and colleagues (2006) this is particularly the case for those children and young people living with parental mental illness. In addition, fluctuations in the health care needs of recipients can temporarily place greater demands on young carers than usual, heighten their anxiety and create a sense of uncertainty within their lives - challenges which have only recently begun to be formally addressed by statutory service providers via the Care Act (2014). Consequently, in order to better understand their daily living experiences, this paper reflects upon young carers' insights of and responses to specific illnesses and/or disabilities and the impact these have on the intimate relationships they share with care recipients.

\section{The Study}

The research findings in this paper are part of a broader study, which focused on identifying the protective and risk factors, which might help to promote or challenge the resilience of young carers. Barnardo's Young Carers and Action for Children Young Carers Projects facilitated the study. Parents, school staff, social workers or general practitioners were most frequent referrers and young carers were provided with a range of services including counselling, group activities, advocacy services, referrals to additional NGOs and other bespoke individual opportunities following assessment of needs.

The aim of the study was to identify the factors which contributed to or challenged the resilience of young carers and involved: exploring young carers' perceptions of care recipients' illness and/or disability; determining the importance of multiple role identities for young carers; utilising a social ecological model to identify the systems of support and resources which young carers regarded as important in assisting in their caring roles; investigating the role of interdependence and reciprocity within young caring relationships; examining the cultural and family context of young carers' lives and to inform policies and practices designed to underpin the resilience of young carers. The research received ethical approval from the Office for Research Ethics Committees Northern Ireland and the School of Sociology, Social Policy and Social Work, Queen's University Belfast. 


\section{Methodology}

Initial approaches were made to Barnardo's Young Carers and Action for Children Young Carers Projects along with the Health and Social Care Board (NI) in order to negotiate access to study participants. Both organisations agreed to take part in the research, recruiting between twenty and thirty young carers to capture a wide range of diverse caring experiences and perspectives. Other recent qualitative studies have reported engaging with similar numbers of children and adults (Grove et al., 2017), using similar means to access research participants (Heyman and Heyman, 2013).

Support staff made contact with potential research participants and their parents and invited them to take part in in-depth semi-structured interviews. Young carers were provided with age appropriate information sheets about the research; information leaflets were also supplied to their parents and support staff answered any questions, which they raised about the research. Potential participants were also assured that if they chose not to take part in the research or withdrew from it at any time; it would not impact upon the services, which they received from the projects. The assent of young carers and the consent of parents were secured before the interviews took place.

The data was gathered over a period of thirteen months with interviews scheduled to coincide with young carers' normal attendance at the projects or at times which did not impinge on their caring roles or other social activities. As Kutrovatz (2017) highlights, children of the same age can be quite diverse in terms of skills and competence and therefore, special attention was paid to the individuality of each research participant and their development stage throughout the interview process regardless of chronological age.

Each young carer participated in an in-depth semi-structured interview containing open-ended questions. The questions drawn up for the interview schedule were developed from the pre-existing literature on resilience and young caring. The interviews were digitally audio recorded and manually transcribed verbatim. 
The findings of the study proved to be extremely compelling, generating a complex body of information on young carers' experiences of ill health and disability. Thematic analysis was used to organise and describe this data. Transcription of the interviews, and their repeated reading enabled the identification of basic themes which were then grouped into higher order codes to provide a broad thematic landscape of the data (Castleberry and Nolen, 2018, p. 4) from which eight non-hierarchical and interconnected themes identifying potential protective and risk factors were created and labelled.

Although each caring relationship may be considered unique and context bound (McDougall et al., 2018) the data enabled the researchers to identify similar substantive caring experiences shared by young carers. Thus, while co-morbidity was experienced by the majority of care recipients, young carers tended to focus on the aspects of ill health or disability which appeared to have the greatest impact on their lives or, if supporting both a parent and sibling, emphasised the nature of their caring roles with the latter. Three core themes highlighting young carers' experiences of parental mental illness, parental physical ill health or disability and sibling care are discussed below.

While the small scale of the study precludes the findings from being generalizable, they may be amenable to some degree of transferability (Ungar, 2003) and also support the findings of similar studies (see for example, Grove et al., 2017 or McDougall et al., 2018). However, as Phelps (2017, p. 119) comments, 'the voices we have heard ...are primarily from young carers ...who are accessing support from a dedicated young carer service' leaving the experiences of those who are perhaps the most marginalised and those who were unwilling or unable to participate in the research, unexplored.

\section{The profiles of young carers and their families}

Twenty-two young carers took part in the study. With the exception of one young carer, all were from white Northern Irish backgrounds. Only four young male carers participated in the study, reflecting the gendered nature of informal care (Aldridge, 2018 and Ilsley, 2013). The young carers represented a wide range of caring contexts and 
offered opportunities to identify factors, which had the potential to contribute to or challenge their resilience.

Of the twenty two participants, eleven indicated that they were caring for more than one person, most frequently their mother and a sibling; twelve confirmed they were living with both of their parents while the remaining ten resided in single parent households. Seven of these ten young carers confirmed they had no contact with their absent parents, two indicated that they met with them very occasionally while one maintained regular contact with her father. The majority of adult care recipients often experienced a combination of wide ranging mental and physical health problems. Care recipients under eighteen were also living with a variety of conditions including cerebral palsy, ADHD and autism. Just over a third of young carers revealed that while they were providing care and support for one or more care recipients, they also took on childcare responsibilities for other younger children living within the household with the greatest burden of childcare care falling on those residing in single parent households.

Most young carers indicated that they had been caring for lengthy periods of time (most frequently between seven and ten years) and specifically in respect of the care of disabled siblings, since they themselves had been three or four years of age. Several revealed that they could not recall a time when they had not been providing some level of informal care and appeared to have been socialised into caring roles from an early age. Moreover, until they had been identified as young carers by either Barnardo's or Action for Children, it was apparent that they had simply regarded the provision of informal care giving as a normal part of everyday life and did not realise that the roles which they were fulfilling were quite different to those undertaken by children and young people in the general population. During interviews it became apparent that asking young carers to estimate the number of hours which they spent providing care was pointless as their roles and responsibilities were often affected by fluctuations in the health and well-being of care recipients, the willingness or capacity of others to provide support and the educational demands placed upon them in relation to the completion of homework or coursework. The data is presented in tabular form in the Table below (all names are pseudonyms). 
Table here

\section{Caring for parents experiencing mental illness}

Almost a third of the young carers involved in the study indicated that they were providing care for at least one family member, usually a parent, with extremely complex health problems. While the aetiologies of such health difficulties were often physical, it was frequently the case that their longevity led care recipients to experience concomitant periods of sporadic or protracted, mental illness, which appeared to further compromise their overall sense of well- being. In total, sixteen children and young people confirmed they were living in households where a care recipient experienced some degree of difficulty with their mental well-being.

It was apparent that mental illness compromised the capacity of a number of parents to provide some degree of reciprocal support to their children, particularly when young carers themselves were experiencing high levels of emotional need. Several young carers recalled how, when they tried to discuss issues which had had a profound effect on their lives, including family breakdown or the loss of a parent through separation or death, care recipients would often become tearful and feel unable to offer them reassurance or meet their emotional needs as the following comments illustrate:

I just, I don't really tell her stuff, like if I'm annoyed...I don't tell her because she just, she'll cry - like her reaction to anything is to cry you know, it's just like, it's insane. You know, me and my sister just get so frustrated with it... (Alana, aged 15, discussing her mother)

She does try to be strong for you, but she can't, ... it's just her depression makes her unable to be, to be strong for you. So, ... you're having to be strong for her, try to stay strong for her. It's like the other way round ... 'cause you don't want to cry 'cause sometimes when I cry, she cries more...sort of thing...I try to be strong for her instead. (Lisa, aged 14, referring to her maternal aunt)

Some young carers were also aware that their parents had experienced challenging childhoods, spending periods of time in care or, being subjected to child abuse and attributed many aspects of their parents' mental health difficulties to these traumatic 
experiences. Despite the frustration which the majority of young people felt in respect of their parents' mental health difficulties and their incapacity to function in what they perceived to be a normal manner, they were nevertheless, clearly moved by and expressed a great deal of compassion in relation to the plight of their parents, outlining how they tried to provide them with emotional support and reassurance. At times, this included talking over problems or trying to engender a more optimistic atmosphere within the household. On other occasions, it involved reassuring parents that they were valued and trying to instil in them a sense of self-worth and personal efficacy as this account recalled by Catherine aged fourteen and caring for her father reveals:

Once, we were in the factory shop in town, and we were just walking and then he suddenly started crying and I was like, what's wrong? And he's like, I'm so useless, I can't give you money and everything and, I had to take him out of the shop and convince him that he wasn't useless and everything.

Others outlined how when suffering from episodes of depression, their parents experienced severe mood swings and, as has been suggested by Monds-Watson and colleagues (2010), appeared to have limited insight and understanding of their situation, as the following excerpt illustrates:

...he doesn't hit us anymore, but he'd be more verbally abusive and emotionally abusive which is probably the most difficult to deal with... he'd call me worthless and just a waste of space and like, a fat slob that gets in the way and stuff like that. It really upsets me.

Young carers learned to cope with these outbursts by becoming more intuitive in respect of identifying behaviours, body language and/or a change of atmosphere within the home, which were indicative of and frequently preceded an emotional episode. In anticipation of such behaviour, they either retreated to their bedroom, went out walking for prolonged periods of time or alternatively, asked friends if they could visit their homes until the situation had diffused - thus putting what Chikhradze and colleagues (2017) describe as both spatial and emotional distance between themselves and their parents. One young carer, Sarah aged seventeen, whose father was living with the long term effects of several strokes coupled with severe depression, likened living with him to being on a roller coaster commenting that: 
...there's times there's just like, no working with him or speaking to him, you know he'll just be in a foul mood for two or three days then he'll just wake up one morning and be back to what we call normal.

Sarah described how she adjusted her behaviour in response to his demeanour when he was feeling particularly depressed. Eventually, Sarah was referred to Child and Adolescent Mental Health Services as a result of the impact her father's health had had on her own mental well-being. Two other young carers caring for parents experiencing mental health difficulties, revealed that they had self-harmed as a means of coping with stress, while a third described how, at the age of twelve when feeling totally overwhelmed with the unpredictable nature of her aunt's mental health problems and other personal issues, she attempted to take her own life. These findings support the assertions of Grove and colleagues $(2017$, p. 250) that children living with a parent with mental illness can be at an elevated risk of developing maladaptive coping skills.

In contrast, some young people's experiences of parental depression appeared to be quite the opposite: they described their parents as becoming extremely quiet and withdrawn, sleeping a great deal and having little interest in everyday activities. When asked about any changes in her mother's demeanour, which might signify she was becoming unwell, Orla aged sixteen commented:

I don't know...you just notice there's a change of atmosphere in the house ... her tablets would cause her quite a lot of drowsiness ... so she would sleep a lot.

The protracted nature of mental health difficulties also led some care recipients to become increasingly socially isolated and it was evident that this also impacted upon the children and young people involved in their care, particularly when they were residing in lone parent households. These young carers revealed that their parents had few if any friends and spent the majority of their time alone at home, while their apparent lack of self-efficacy resulted in their avoidance of tasks which involved social interactions such as weekly shopping or enrolling their children in clubs or leisure activities.

Five young carers indicated that they had been living with parental mental illness their entire lives, and, where this was typified by low moods, had become so accustomed to their parents' melancholic behaviour that they responded to it in an essentially dispassionate and detached manner: they had simply become used to it. As a 
consequence, it was frequently the case that young people described the relationships they had with their parents in largely pragmatic terms, discussing how they had provided them with a home, food, clothing and pocket money. They also confirmed that they made important decisions, including educational choices, without any input from their parents. Several young carers also commented that when their parents were feeling more positive, they did experience some degree of intimacy with them - however short lived. It is worthy of note that there was little evidence to indicate health or social care professionals ever invited young carers to raise any concerns or ask any questions which they had in respect of their parents' mental health problems or to address their own distinct emotional needs.

\section{Caring for parents experiencing physical ill health and/or disability}

Parents who suffered from physical ill health and/or disabilities had a much greater capacity to regulate their own health and well-being than those suffering from mental illness. These parents tended to reside in households, which were well organised and maintained in respect of daily living activities. Within the majority of such households both parents were present, care was shared between a parent and one or more young carer and the overall environment of the home appeared cohesive and supportive although some care recipients were frustrated by the limitations which their illnesses imposed upon them. However, the majority of children and young people who took part in the study stressed that they felt their parents pushed themselves on as much as possible within the confines of their health problems and this tended to enable them to rationalise and accept their caring role.

She just takes every day as it comes ... she's just got like, a really positive view of things, she just battles on every day ... it's inspirational. (Eve aged fifteen, caring for her mother with MS).

Young carers had also become intuitive in respect of anticipating when care recipients needed to rest, encouraging them to do so in order to avoid any further deterioration of their health and an escalation in their own levels of anxiety. In several 
households, entire families were involved with the provision of care due to the severity of parental illness.

In a number of instances where young people perceived illnesses to be either life threatening, or where the overall prognosis was poor, their distress was palpable. For example Elizabeth, aged 13, caring for her mother with long term liver disease and her younger brother who had sensory and mobility difficulties, expressed great anxiety at the likelihood of her mother requiring a liver transplant in the future:

I worry if she does get a liver transplant and it doesn't go well - what's going to happen to all of us, what's going to happen to us, what are we going to have to do? Am I going to have to stay at home and watch Alan or am I going to be able to go to school? I worry about all of that.

Eleven young carers were providing care for more than one person - most often a parent and a sibling. Those parents who had a child experiencing some form of physical or intellectual disability made every effort to care for them within the limitations imposed by their own ill health. While young carers were clearly bolstered by this, they also felt obliged to take on additional responsibilities in an effort to lessen the pressure on their parents, particularly when their health was worse than usual. For example, as her mother's health began to decline Lesley, aged seventeen described how her caring responsibilities for her younger sister who had cerebral palsy increased:

I would have had thirty per cent, and she would have sixty per cent, but well now, it's got to fifty/fifty or a tiny bit more - sixty/forty or whatever.

These findings contrast with those highlighted in research, which suggests that when a disabled family member is a sibling, children and young people will tend not to become primary carers but rather, will adopt what Thomas and colleagues (2003) describe as a secondary or supportive role. While this may be the case in households in which the only care recipient is a child or young person, the findings generated by this study suggest that in families where illness or disability affect more than one person, caring responsibilities can be experienced as much more fluid and in some circumstances become a shared care arrangement. The nature of illness and disability do not necessarily remain constant but rather, may be marked by fluctuations and periods of increased need 
which are not always foreseeable and, when juxtaposed with changes in family structure, begin to provide a sense of the complexity of caring relationships.

\section{Caring for siblings living with developmental disorders}

Unpredictable and challenging behaviours were also experienced by young people caring for siblings with some form of autism, an issue attracting research interest (see for example, Poppes et al., 2010; Rzepecka et al., 2011, and Research Autism, 2016). While the symptoms manifested by individuals living with autism vary widely, it was those young carers whose siblings were physically aggressive who appeared to have the greatest difficulty in managing their caring roles. Several young people recounted incidents in which they were punched, kicked, slapped and bitten or were actively involved in restraining their siblings to prevent them from causing further injury to others or damaging household property. During one interview, Oliver aged seventeen, whose eighteen year old brother Kieran suffered from what he described as classical autism recounted the extremities which his behaviour had reached in the past:

Whenever he was really bad you know, there were incidents whenever he just, he went so mental and did so much kind of damage, you just, you can hardly believe it like. You were just sort of taken aback and you were kind of frightened.

Kieran's physical attacks on family members were a frequent occurrence and took place on a regular basis. While Oliver acknowledged that he understood why his brother behaved as he did, he also indicated that he was also anxious when his two younger siblings aged twelve and thirteen were left alone with their brother even for ten minutes.

While not all of those young people caring for siblings with autism experienced violent or destructive outbursts, they did identify associated difficulties such as problems with personal hygiene, fixations on specific subjects or foods, inability to interpret other people's feelings or failing to recognise when they were behaving in a socially offensive manner. The latter of these problems tended to result in rejection or bullying by peers, which young carers found upsetting. As a result, they often tried to moderate or alter their siblings' behaviour in order for them to be regarded as more socially acceptable while at the same time, shielding them from verbal abuse. One young carer, Carol, now aged 
seventeen, recounted how both she and her sister had to leave their primary school and enroll elsewhere because of the persistent bullying to which they were subjected as a result of her younger sibling's autism.

Despite facing such challenges, young carers tried to encourage their siblings to develop self-confidence and to tackle tasks; taking on something of a mentoring role. It was evident that they took a great pride in their achievements, particularly when it involved the child or young person in question attaining a level of success that had previously been anticipated as beyond their capabilities. Overall, for the majority of young carers, being involved with the provision of informal care had enhanced their relationships, generating closeness with siblings. Most young carers recognised and accepted that their siblings could do little to reciprocate the care which they provided them, but even small acts of gratitude including being hugged, having their hair straightened, playing card games and other little stuff were warmly received and valued as an acknowledgement and appreciation of their caring roles.

...there'd be days she'd just come down to my room and bring me down a wee cup of tea or like, a drink of Coke or crisps. She never used to do anything for me so, I'm like, grateful she does a wee bit in return. (Carol aged seventeen, caring for her sister aged fourteen)

While such modest gestures might appear insignificant in proportion to the demands placed on young carers, as Gilligan (2000) asserts, it is the cumulative effects of many little things or what Masten (2001) terms ordinary magic that in combination, are regarded as sufficient to enhance resilience.

\section{Conclusion}

The research confirms that the nature of caring relationships is complex, with the psychological impact appearing to be the most challenging aspect of young carers' roles. For those children and young people living with parental mental illness, whether subject to unpredictable behaviour or experiencing parental withdrawal from many aspects of daily living, the overall impact was similar, with young carers having little emotional support and only the most tenuous attachment to their parents - psychological needs 
which under ordinary circumstances act as a springboard to the wider world (Daniel and Wassell 2002, p. 28). In contrast, in households where care recipients experienced mainly physical illness or disability, the gravity of their conditions and their future health trajectories (and potentially those of some young people themselves) did gave rise to heightened levels of anxiety amongst young carers but did not seem to expose them to the same levels of adversity as those caring for parents with protracted mental health difficulties. It was evident that caring for siblings with progressive developmental disorders also had psychological implications for young carers, with fear of social rejection and isolation being the most obvious with sibling violence, almost a bi-product of these relationships that appeared to be superseded by the bonds of love and affection. Adverse experiences, however, by virtue of their protracted, volatile and insidious nature, have the potential to seriously compromise the well-being of entire families.

While the focus of this paper has concentrated on exploring young carers' knowledge of and responses to the nature and trajectory of illness or disability, it is recognised that these findings represent only a glimpse into of one of the multi-factorial determinants which combine to influence young carers' capacity for resilience; the original study from which these findings were generated also identified amongst others factors, the loss of contact with or rejection by a biological parent, exposure to domestic violence, parental misuse of alcohol and/or drugs, child abuse and being taken into care as additional adverse experiences leading to the diminution of resilience (Author's own, 2017). This confirms the fact that the impact of caring is not something which can easily be extricated from myriad experiences both past and present, which combine to influence the lives of young carers.

Although the small scale of the study renders its findings ungeneralisable, it does confirm that the nature and trajectory of illness have the potential to expose some subpopulations of young carers to greater adversity than others. This has implications for those charged with supporting young carers in their caring roles and emphasises the fact that until policy initiatives move beyond purpose based statements and a preoccupation with what Byng-Hall (2008) describes as instrumental tasks, the differential needs of young carers may remain unacknowledged and regarded as low priority by social service providers (Morgan, 2006). Indeed, several young carers recounted that it was only when they exhibited behavioural difficulties in school or their attendance was particularly poor 
that they came to the attention of statutory service providers. As previously outlined, another explained it was not until she attempted to take her own life at twelve years of age that she was provided with formal counselling and appropriate guidance on living with parental mental illness. These findings appear to substantiate the position of Authors own (2012, p.1582) that a preoccupation with child abuse and neglect may lead to the majority of 'Children in Need', whose circumstances fail to meet child protection thresholds...[receiving] few if any services.

While young carers have now legislative support to have their needs assessed, this process depends on social workers identifying young carers or, alternatively young carers or their parents self-referring to services, which requires an awareness of the right to assessment. Clearly, the covert nature of many caring roles has the potential to delimit this process, so too the failure of some young carers and their families to recognise themselves as such. Further, the focus of initial assessments on the immediacy of caring roles and the nature of their impact on young carers may result in the decontextualization of care and a failure to identify additional adverse experiences which need to be factored into the knowledge base on children and young people with caring responsibilities (Author's own, 2017). Therefore, in order to make prudent decisions regarding the targeting of interventions, there is a need to ensure the lived experiences of young carers, both past and present, are drawn together to inform a more comprehensive assessment process to assist social workers to needs in order to most effectively target resources. To employ an old fashioned social work term, we need to be able to see beyond the presenting problem, to understand the lives of these young people in ways which appreciate the impact upon them of caring as not just a practical, but also a psychological task. The comments of the young people reported in this study reveal the often traumatic nature of their experience, inviting interventions that should be aimed at building not just their capacity to cope but also seek ways to ameliorate the impact of caring upon them both now and into the future - suggesting that interventions should be characterised by services delivered over long terms.

\section{Acknowledgements}


Without the co-operation of the young carers who took part in the research, this study would not have been possible. Our gratitude is extended to them and their families, to Action for Children Young Carers Project, Barnardo's Young Carers Project and the Health and Social Care Board [NI].

\section{References}

Authors own 2012

Authors own 2017

Aldridge, A. (2018) 'Where are we now? Twenty-five years of research, policy and practice on young carers', Critical Social Policy, 38 (1), pp. 155-165.

Aldridge, J. and Sharpe, D. (2007) Pictures of Young Caring, Loughborough, Young Carers Research Group, Loughborough University.

Becker, S. (2007) ‘Global Perspectives on Children's Unpaid Caregiving in the Family: Research and Policy on 'Young Carers' in the UK, Australia, the USA and Sub-Saharan Africa', Global Social Policy, 7(1), pp. 23-50.

Bradford, B.B. and Larson, J. (2009) Handbook of Adolescent Psychology, New York, John Wiley and Sons.

Byng-Hall, J. (2008) 'The significance of children fulfilling parental roles: Implications for family therapy', Journal of Family Therapy, 30, pp. 147-163.

Castleberry, A. and Nolen, A. (2018) 'Thematic analysis of qualitative research data: Is it as easy as it sounds?', Currents in Pharmacy Teaching and Learning, In Press pp. 1-9. 
Chikhradze, N., Knecht, C. and Metzing, S. (2017) 'Young carers: growing up with chronic illness in the family - a systematic review 2007-2017', Journal of Compassionate Health Care, 4(12), pp. 1-16.

Cooklin, A. (2009) 'Children as carers of parents with mental illness', Psychiatry, 8(1), pp.17-20.

Day, C. (2015) Young adult carers: a literature review informing the re-conceptualisation of young adult caregiving in Australia, Journal of Youth Studies, 18(7), pp. 855-866.

Department of Health, Social Services and Public Safety (2006) Caring for Carers: Recognising, Valuing and Supporting the Caring Role, Belfast, DHSSPS.

Department of Health, Social Services and Public Safety (2009) Families Matter: Supporting Families in Northern Ireland. Regional Family and Parenting Strategy, Belfast, DHSSPS.

Devine, P. and Lloyd, K. (2008) Young Carers, ARK Research Update 56, Belfast, ARK. www.ark.ac.uk/publications/updates/update56.pdf [Accessed 10/4/10]

Devine, P. and Lloyd, K. (2011) Young Carers Too, ARK Research Update 76, Belfast, ARK. www.ark.ac.uk/publications/updates/update76.pdf [Accessed 8/2/12]

Duffy, J., Basu, S., Davidson, G. and Pearson, K.C. (2014) Review of Legislation and Policy Guidance Relating to Adult Social Care in Northern Ireland, Belfast, Commissioner for Older People Northern Ireland.

Earley, L., Cushway, D. and Cassidy, T. (2007) 'Children's perceptions and experiences of care giving: A focus group study', Counselling Psychology Quarterly, 2(1), pp. 69-80.

Fives, A., Keenan, D., Canavan, J. and Brady, B. (2010) Study of Young Carers in the Irish Population. Main Report, The National Children's Strategy Research Series, Dublin, Government Publications. 
Gilligan, R. (2000) 'Adversity, Resilience and Young People: The Protective Value of Positive School and Spare Time Experiences', Children and Society, 14, pp. 37-47.

Gilligan, R. (2009) Promoting Resilience: Supporting children and young people who are in care, adopted or in need, London, British Association for Adoption and Fostering (BAAF).

Gladstone B.M., Boydell K. M., and McKeever, P. (2006) 'Recasting research into children's experiences of mental illness: Beyond risk and resilience', Social Science and Medicine, 62, pp. 2540-2550.

Grove, C., Riebschleger, Bosch, A. and Cavanaugh, D. (2017) 'Expert views of children's knowledge needs regarding parental mental illness', Children and Youth Services Review, 79, pp. 249-255.

Heyman, a. and Heyman, B. (2013) 'The sooner you can change their life course the better': the time-framing of risks in relationship to being a young carer', Health, Risk \& Society, 15(6-7), pp. 561-579.

Ilsley, B. (2013) Unfinished Business, Public Policy and children in families with a person with a disability or mental illness, Footscray, Victoria, 3011, Carers Victoria.

Kutrovatz, K. (2017) 'Conducting Qualitative Interviews with Children - Methodological and Ethical Challenges', Corvinus Journal of Sociology and Social Policy, 8(2), pp. 65-88.

Lane, T., Cluver, L., and Operario, D. (2015) 'Young carers in South Africa: Tasks undertaken by children in households affected by HIV infection and other illness', Vulnerable Children and Youth Studies, 10(1), pp. 55-66.

Lloyd, K. (2012) 'Happiness and Well-Being of Young Carers: Extent, Nature and Correlates of Caring Among 10 and 11 Year Old School Children', Journal of Happiness Studies, 14, pp. 67-80. 
Masten, A.S. (2014) Ordinary Magic, Resilience in Development, New York, The Guildford Press.

McDougall, E., O'Connor, M. and Howell, J. (2018) ' "Something that happens at home and stays at home": An exploration of the lived experience of young carers in Western Australia', Health Soc Care Community, Feb.19 [Epub ahead of print].

Meltzer, A. (2017) ' 'I couldn't just entirely be her sister': the relational and social policy implications of care between young adult siblings with and without disabilities', Journal of Youth Studies, 20(8), pp. 1013-1027.

Monds-Watson, A., Manktelow, R. and McColgan, M. (2010) 'Social Work with Children when Parents have Mental Health Difficulties: Acknowledging Vulnerability and Maintaining the "Rights of the child"', Child Care in Practice, 16(1), pp. 35-55.

Morgan, R. (2006) Being a Young Carer: Views from a young carers' workshop, Newcastle upon Tyne, Commission for Social Care Inspection.

Patient and Client Council (2011) Young Carers in Northern Ireland. A report of the experiences and circumstances of 16 year old carers, Belfast, Patent and Client Council. www.patientclientcouncil.hscni.net/uploads/research/Young carers in Northern Ireland.pdf [Accessed 4/6/12]

Phelps, D. (2017) 'The Voices of Young Carers in Policy and Practice', Social inclusion, 5(3), pp. 113-121.

Poppes, P., Putten, A. J. J. and Vlaskamp (2010) 'Frequency and severity of challenging behaviour in people with profound intellectual and multiple disabilities', Research in Developmental Disabilities, 21, pp.1269-1275.

Research Autism (2016) Essential Guide to Challenging Behaviours and Autism. http://www.researchautism.net/publicfiles/pdf/essential-guide-autism-challengingbehaviours.pdf [Accessed 12/5/18] 
Rzepecka, H., Mckenzie, K., McClure, I. and Murphy, S. (2011) 'Sleep anxiety and challenging behaviour in children with intellectual disability and/or autism spectrum disorder', Research in Developmental Disabilities, 32(6), pp. 2758-2766.

Ungar, M. (2003), 'Qualitative contributions to resilience research', Qualitative Social Work, 2(1), pp. 85-102. 